\title{
Increase Visibility for Motorcyclist Detection at Night for the Purpose of Avoiding Accidents Using a Simple RF Circuit
}

\author{
M. F. Basar and N. H. A. Razik, Member, IACSIT
}

\begin{abstract}
This paper describes the effectiveness of Smart Motorcycle Safety Vest (SMS-V) for motorcyclist in Malaysia. The SMS-V is the reflex of light shirts and fitted with red and bright yellow LEDs which become the third light for brake and signals. Besides that, the SMS-V is employing the simple RF circuit which is not expensive. According to statistics of road accidents in Malaysia, accidents involving motorcyclists has a high number and it increases every year. As a result, many young people died and some have suffered permanent disabilities and this is a great loss to society and country. Therefore, there should be an alternative effort to ensure that this group is not a victim in the accident. Basically, the accident on the motorcycle is happened because most of motorcyclist are not concerned about safety where the mistakes that frequently happen is wearing dark colored clothing. According to the research experimental works, a motorcycle can only be known by the headlight and taillight of motorcycle at a distance of less than 180 meters. If a vehicle such as car and lorry at a speed of $90 \mathrm{~km} / \mathrm{h}$ faced with a motorcyclist, the vehicle only has 6 seconds to be alert to the presence of motorcyclists. Instead, this product able to assist road users about the presence of a motorcyclist at a distance of 500 meters, which is three times better than normal conditions. Based on motorcycle registration statistics released by the Malaysian Road Transport Department, as at January 2012, almost 10 million motorcycles were registered in Malaysia. If SMS-V is used only $50 \%$ of the number stated above, roughly, it will become a fashion and give a great impact to the motorcyclists as the product itself offers an interesting look. Hence, it is believed that this research is able to reduce the number of road accidents which often happen to motorcyclists in Malaysia
\end{abstract}

Index Terms — Light emitting diode, motorcyclist, third light, safety vest, Malaysia.

\section{INTRODUCTION}

Road accidents have caused huge losses to the country. It involves an injury, suffering and death but the histories of road accidents seem endless in Malaysia. Thus, the desire to travel safely and smoothly remains as intention of the government and the individual road users. Therefore, currently many different efforts have been developed to avoid vehicle crash on the road especially that involve with motorcyclists. In Malaysia, $96 \%$ of injuries and deaths from

Manuscript received January 21, 2013; revised March 25, 2013. The authors would like to express sincere gratitude to Universiti Teknikal Malaysia Melaka (UTeM), Malaysia for sponsored the fees for Malaysia's patent filling application. The patent filing number: PI201100001.

The authors are with Faculty of Technology Engineering, Universiti Teknikal Malaysia Melaka (UTeM), Hang Tuah Jaya, 76100 Durian Tunggal, Melaka, Malaysia (e-mail: mfarriz@utem.edu.my, hazana@utem.edu.my). accidents are caused by driver carelessness. Fig. 1 shows the example of motorcycle accident in Malaysia.
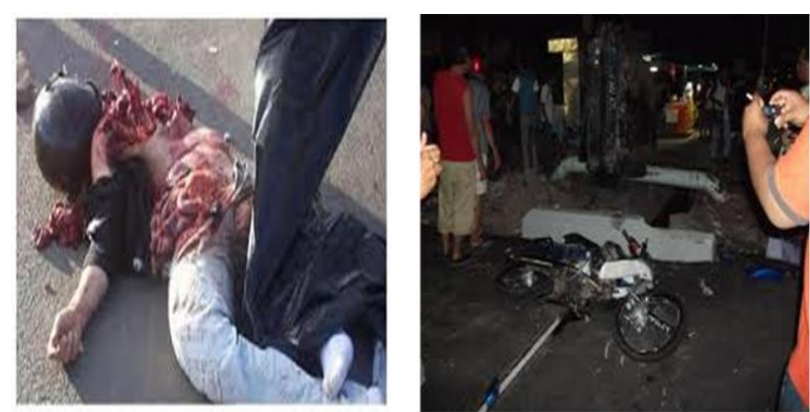

Fig. 1. Motorcycle accident in Malaysia.

TABLE I: STATISTICS OF ROAD ACCIDENTS IN MALAYSIA

\begin{tabular}{|c|c|c|c|c|c|}
\hline \multirow{2}{*}{$\begin{array}{c}\text { Vehicle } \\
\text { Involved }\end{array}$} & \multicolumn{5}{|c|}{ Year } \\
\hline & 2005 & 2006 & 2007 & 2008 & 2009 \\
\hline Motorcycle & 376,061 & 411,976 & 428,475 & 441109 & 472307 \\
\hline Car & 97,072 & 104,302 & 111,958 & 113381 & 113962 \\
\hline Van & 19,031 & 20,465 & 21,187 & 20501 & 19220 \\
\hline School Bus & 1,106 & 1,235 & 1,274 & 1134 & 1160 \\
\hline Factory Bus & 1,126 & 1,176 & 1185 & 1120 & 864 \\
\hline $\begin{array}{l}\text { Express } \\
\text { Bus }\end{array}$ & 1,836 & 2,156 & 2,091 & 2056 & 2348 \\
\hline Small Lorry & 12,372 & 13,915 & 17,464 & 18290 & 16459 \\
\hline Lorry & 20,284 & 20,406 & 19,138 & 18262 & 19188 \\
\hline $\begin{array}{l}\text { Trailers and } \\
\text { Tanker } \\
\text { Trucks }\end{array}$ & 9,406 & 10,494 & 11,193 & 11101 & 11077 \\
\hline $\begin{array}{l}\text { Four-wheel } \\
\text { Drive }\end{array}$ & 19,106 & 20,928 & 22,018 & 22656 & 23581 \\
\hline Taxi & 7,043 & 7,754 & 8,816 & 8816 & 8669 \\
\hline Bicycle & 2,751 & 2,857 & 2,693 & 2443 & 2486 \\
\hline $\begin{array}{l}\text { Total of } \\
\text { Vehicle } \\
\text { Involved }\end{array}$ & 581,082 & 635,082 & 668,173 & 676114 & 705623 \\
\hline
\end{tabular}

The invention basically is well suited for motorcycle rider, where the safety vest (SMS-V) equipped with the third safety brake LED light, left and right signal LED light and LED taillight that is more transparent to road users. The reason why LED light is used because most of the road accident happens due to visibility where the road user could not see the presence of the motorcyclist in front or next to them.

Obviously, the major factor to road accidents is the result of failure of the road user himself when on the road. Table I shows the Statistics of Road Accidents in Malaysia referred 
to the Driving Education Curriculum from Road Transport Department of Malaysia (JPJ) where the number of road accidents involving motorcyclists has a high number and it increases every year [1]. As a result, many young people died and some have suffered permanent disabilities. This is a great loss to society and country as they are the heirs and human capital for national development.

\section{Methodology}

Generally, the research works consists of literature review on previous work, development of RF controller circuit, design and development smart vest attached with LED and finally field experimental tests. The purpose of adopting the research methodology is to obtain the desired experimental results during the field experimental work. The main intention of this research is to develop a safety vest that can be used as the third light for brake and signal of the motorcycle, where it is facilitated with wireless technology.

In the Stage 1, the materials and components are assemble to develop the transmitter and receiver controller circuit using the RF technology. The transmitter controller circuit is located under the seat of motorcycle and the receiver is attached at safety vest. Then, in Stage 2, the white, yellow and red LED strip is attached to the safety vest. In addition the LEDs are connected with the receiver controller box. In final stage, the field testing is conducted in order to investigate the performance of SMS-V and the field testing was conducted at night. Besides that, the testing has been done to compare the effect of both with and without innovative safety vest. Analysis is carried out to verify the performance of SMS-V. The analysis is aligning with the reliability and functionality of the RF controller box in the SMS-V.

\section{LITERATURE REVIEWS}

Nowadays, global economic crisis already becoming a gigantic anxiety for some countries in the world. In general, almost medium earners have to change their lifestyle including the vehicle they ride. Due to that, the numbers of motorcycle riders has increased dramatically, which also the demand of high quality light vest becomes imminent. Nearly half of accident occurred correspond to the motorcycle riders are due to the visibility of these motorcycle rider to the other road users. During night, fog and even haze, the risk increase as the traffic visibility become less.

Most of these transportation deaths and injuries occur on the nation's highways. The United Nations has ranked Malaysia 30th among countries with the highest number of fatal road accidents, registering an average of 4.5 deaths per 10,000 registered vehicles. The effect of variety of road condition contributes to road accidents. In addition, lane detection is not easy due to the varying road condition while driving. For that reason, one of the main technology involves is computer vision which become a powerful tool for sensing the environment and has been widely used in many application by the intelligent transportation systems (ITS) [2]-[4]. However, optical sensors and computer vision is quite expensive and for that reason SMS-V project is employed the RF technology.

Nowadays vehicle detection and shape recognition based on optical sensors has becoming an area of active research among researcher and development departments of civil defense, traffic police and universities. A successful vehicle detection and shape recognition algorithm will pave the way for vehicle recognition, vehicle tracking and safety improvements [5]-[8].

In addition, many inventors have come out with many inventions of jacket, vest and traffic signaling system. Reference [9] shows a motorcyclist garment with illuminated traffic signals comprising: a garment having a back side, a neck opening, and arm openings; and a light-emitting assembly. The light emitting diode (LEDs) are powered and triggered by the signal tapped directly from the signal at the motorcycle tail, break and left and right signal fixture. Although the garment conveniently getting the power source from the motorcycle tail, the motorcyclist has inconveniently reconnect and disconnect when they embark and disembark from the motorcycle especially when having to do some work which require small time frame such as going to the toilet or automated teller machine (ATM). On the other hand, the SMS-V employs a wireless technology in order to provide comfort to the motorcyclist.

H.G. Ross et al. [10] developed a brake light warning system for safety helmets includes a transmitter module adapted for mounting to a vehicle, such as a motorcycle, and a receiver module adapted for mounting to a safety helmet [9]. The transmitter module is configured to continuously transmit a transmission signal when a brake of the vehicle is disengaged and discontinue transmission of the transmission signal when a brake of the vehicle is engaged. The disadvantage of this invention is the limited application, of only giving a breaking signal to the road users. By having the breaking light warning system on the helmet could cause the system to be very unreliable due to riders occasionally turns their head left or right looking for direction or just distracted by the road objects.

V.M. Pacheco et al. [11] investigated about a traffic signaling device system for motorcyclists comprising a safety brake and running light assembly mounted to a motorcycle jacket [10]. The safety brake light has an L.E.D. housing supported by an outboard support member and a leather piece. The disadvantage of this system is it requires the rider to mount the LEDs on the jacket, connect some wiring to the motorcycle tail and mount the control box to the gas tank or near the motorcycle controls. This is very time consuming and inconvenient to the users.

Ahmad Zaki et al. [12] reported that, a sensor and camera can be used in real time system which proven for visual monitoring and detection purposes. The system consists of sensors, a number of cameras, a GPRS modem and PC where it has microcontroller to which sensors are wired, cameras and GPRS modem that are connected to the personal computer. If the system retrieves data from the sensors and cameras, it sends SMS to users. However, the disadvantage of this system is complex and a bit expensive compare to the simple RF system. 


\section{DeVElopment of InNOVAtive SAFETy VeST}

The smart motorcycle safety vest (SMS-V) as shown in Fig. 7, comprising red LED light for brake, yellow LED light for left and right signal and another red LED for taillight which is embedded in the safety vest. The strip LED is sewed between the materials of the vest in order to have a rigid position.

The most significant concept in this project is the utilization of existing motorcycle signal wiring as the triggering signal for RF transmitter controller circuit in order to activate the LED on the SMS-V. Besides that, the use of wireless controller (RF) for the purpose to transmit the motorcycle signal to the receiver controller circuit located in the vest is also a part of novelties. In addition, the wire connection and arrangement of electronics component including the arrangement of LED strip; the transmitter and receiver controller circuit in the SMS-V is original design. Finally, the way of the transmitter controller box is tap with the existing motorcycle wiring is also a new technique.

\section{A. Stage 1}

The intention of stage 1 is to develop a transmitter and receiver controller circuit for the SMS-V. The controller basically using the radio frequency (RF) technologies with the frequency employed is $40 \mathrm{MHz}$. Transmitter controller box as shown in Fig. 2 is powered by two AA $1.5 \mathrm{~V}$ batteries. This controller need to be attached at the motorcycle and the best place is under the seat of motorcycle.

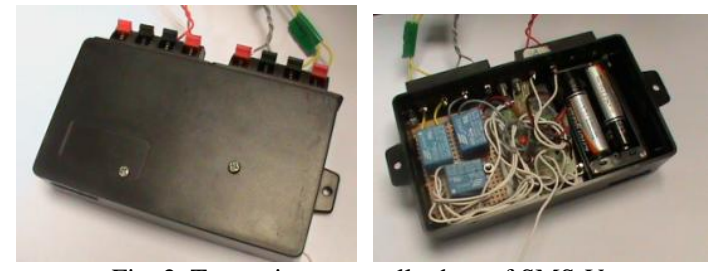

Fig. 2. Transmitter controller box of SMS-V.

Fig. 3 shows the situation before and after the transmitter controller box connected with the motorcycle wiring system. In addition, the transmitter controller box is connected and placed under the motorcycle seat for the reason to provide a convenient and easiness to the motorcyclist and also to prevent the transmitter controller box from any damage.
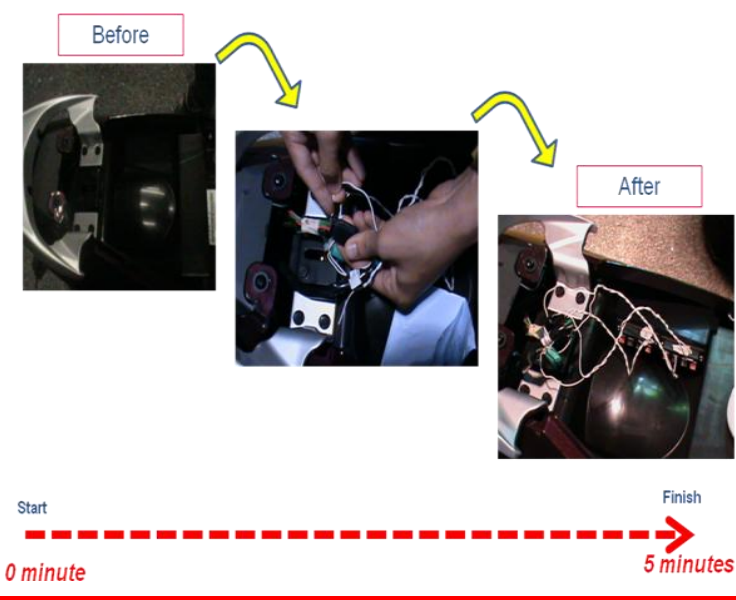

Fig. 3. Transmitter controller box attached in the motorcycle.

Basically, the user has to take only six wires from the existing wiring of the motorcycle. Then connect the six wires to the transmitter controller box as shown in Fig. 4. It is good to know that, most of the motorcycles have the wiring under the seat, thus it is easy to attach the transmitter controller box under the motorcycle seat. The installation of the transmitter controller box can be completed approximately less than five minutes. In addition, the controller box is only need to be installed during the first time used and it is permanently connected.

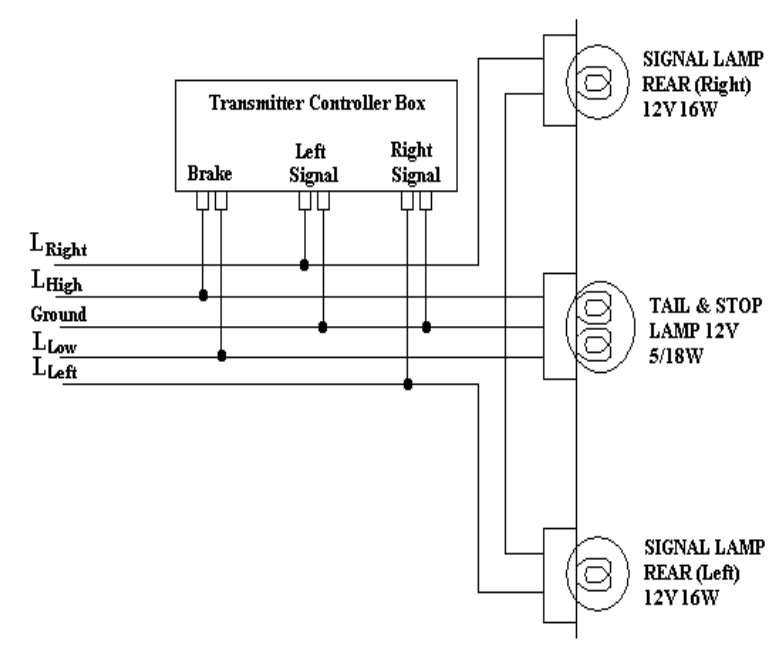

Fig. 4. Transmitter controller box connect to the motorcycle wiring.
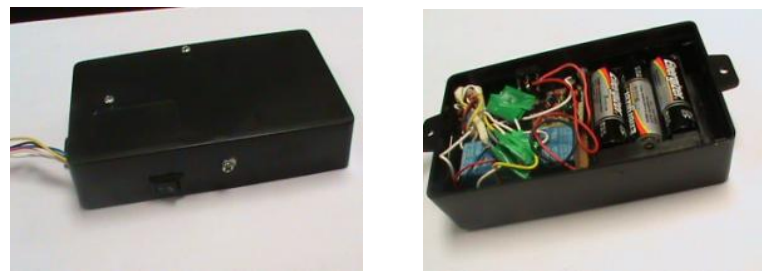

Fig. 5. Receiver controller box.

Fig. 5 depicted the receiver controller box of SMS-V where it is powered by three AA $1.5 \mathrm{~V}$ batteries and this controller is attached inside the vest. Essentially, this controller will receive a signal which is trigger and send out by the transmitter control circuit. Simultaneously, the receiver will activate the circuit for switch on the brake light, left and right signal attached at the SMS-V dependable to the signal send by transmitter.

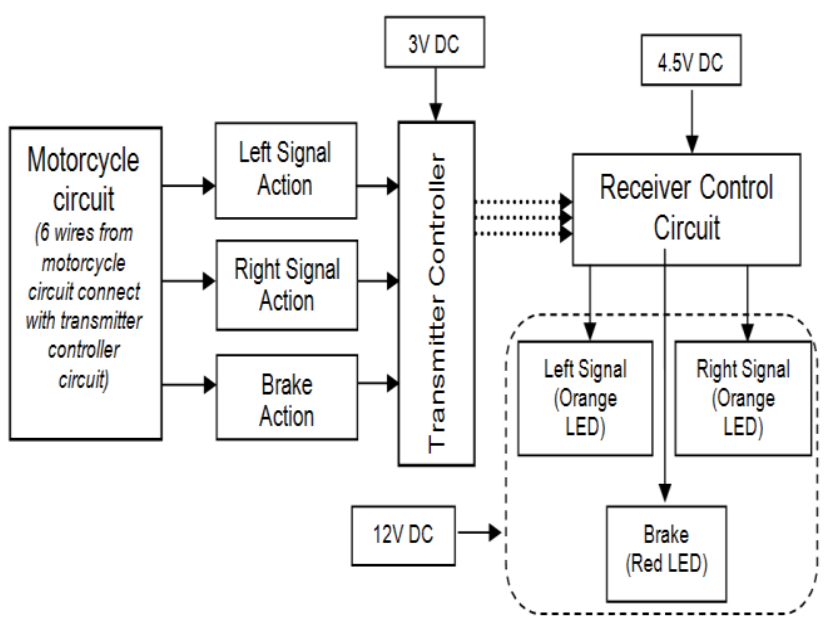

Fig. 6. Wiring diagram of SMS-V system. 
Fig. 6 is the overall working system of the SMS-V. It can be concluded that the system is not complex, inxpensive and easy for troubleshooting if there is any problem in the future.

\section{B. Stage 2}

The innovation safety vest, SMS-V has the strip LED which is sewed within the vest. It has third safety brake LED light, left and right signal LED light and LED tail light powered by a $12 \mathrm{Vdc}$ light weight rechargeable battery that offers high intensity thus excellent visibility to the motorcycle riders. The transmitter controller box is placed under the rider seats, which connected directly to the motorcycle signal. Basically while the rider switch on the brake, left or right button signal at the motorcycle handle, the transmitter controller box will trigger and transmit the respective signal to the receiver controller box located inside the SMS-V and it will respond accordingly.

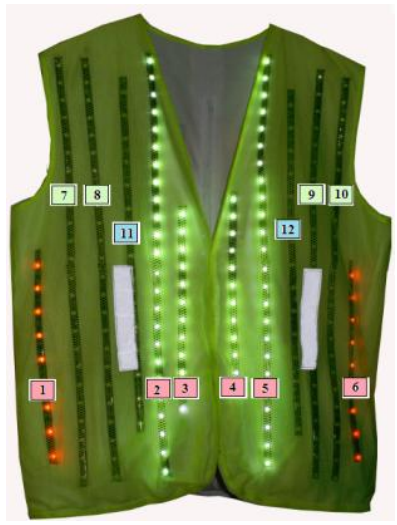

Front

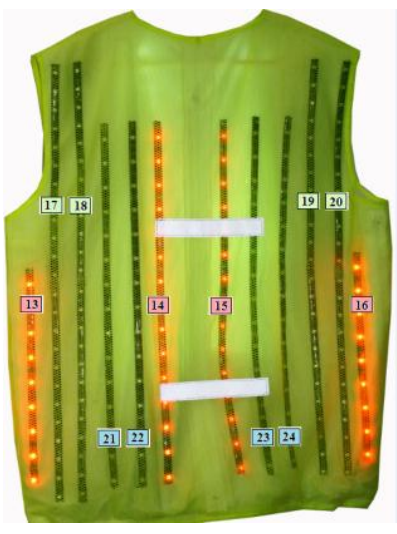

$\underline{\text { Rear }}$
Fig. 7. Front view and rear view of the innovative safety vest.

Referring to Fig. 7, it can be seen that SMS-V comprises a flexible strip LEDs yellow, red and white attached in front of the SMS-V. Number 1 and 6 represent the LED taillight, number 7 and 8 represent right signal LED light, number 9 and 10 represent the left signal LED light and number 11 and 12 represent the brake LED light. In addition, number 2, 3, 4 and 5 is an additional for front light. Besides that, for the rear side of the SMS-V, number 13, 14, 15 and 16 represent the LED taillight, number 17, 18 and 19, 20 represent the left and right signal respectively and number 21 to 24 represent the brake light. The entire LED positive terminal is soldered together according to its function while the negative terminal connected to the ground. All wires were connected directly to the receiver controller box which is powered by dry cell battery AA $3 \mathrm{~V}$. Besides that, the dry cell battery $12 \mathrm{~V}$ is used to power the LED strip of the SMS-V.

At the beginning, rider have to switch the main button inside the vest in order to activate the receiver control box and to turn on the tail light (no 1, 6, 13, 14, 15 and 16) and front light (no 2 -5). During riding, while the rider pulls the front brake, the SMS-V brake light (no 11, 12, 21 - 24) will turn on. While the rider push the right or left signal, the SMS-V right (no 7, 8, 19 and 20) or left (9, 10, 17 and 18) signal will blink respectively. In addition, the LED attached to the vest will blink in the same frequencies with the motorcycle signal.

\section{HIGH RELIABILITY ON THE ROAD}

The field testing activities have been conducted at Universiti Teknikal Malaysia Melaka (UTeM) at night with a real motorcycle on the road in order to investigate the performance of this innovative safety vest. Table 2 shows the time to alert for other vehicle for two different conditions which are with and without the SMS-V. It shows that, by using the SMS-V, time available for other vehicles is more and greater compare with no safety vest.

TABLE II: TIME TO ALERT FOR OTHER VEHICLES.

\begin{tabular}{cccc}
\multicolumn{4}{c}{ TABLE II: TIME TO ALERT FOR OTHER VEHICLES. } \\
\hline \hline \multicolumn{2}{c}{ Without SMS-V } & \multicolumn{2}{c}{ With SMS-V } \\
\hline $\begin{array}{c}\text { Speed of the } \\
\text { Other Vehicle }\end{array}$ & Time to alert & $\begin{array}{c}\text { Speed of the } \\
\text { Other Vehicle }\end{array}$ & Time to alert \\
\hline $50 \mathrm{~km} / \mathrm{h}$ & 10.8 second & $50 \mathrm{~km} / \mathrm{h}$ & 36.0 second \\
$60 \mathrm{~km} / \mathrm{h}$ & 9.0 second & $60 \mathrm{~km} / \mathrm{h}$ & 30.0 second \\
$70 \mathrm{~km} / \mathrm{h}$ & 7.7 second & $70 \mathrm{~km} / \mathrm{h}$ & 25.7 second \\
$80 \mathrm{~km} / \mathrm{h}$ & 6.8 second & $80 \mathrm{~km} / \mathrm{h}$ & 22.5 second \\
$90 \mathrm{~km} / \mathrm{h}$ & 6.0 second & $90 \mathrm{~km} / \mathrm{h}$ & 20.0 second \\
$100 \mathrm{~km} / \mathrm{h}$ & 5.4 second & $100 \mathrm{~km} / \mathrm{h}$ & 18.0 second \\
$110 \mathrm{~km} / \mathrm{h}$ & 4.9 second & $110 \mathrm{~km} / \mathrm{h}$ & 16.4 second \\
$120 \mathrm{~km} / \mathrm{h}$ & 4.5 second & $120 \mathrm{~km} / \mathrm{h}$ & 15.0 second \\
\hline \hline
\end{tabular}

According to the research experimental works, a motorcycle can only be known by the headlight and taillight of motorcycle at a distance of less than 160 meters as shown in Fig. 8.

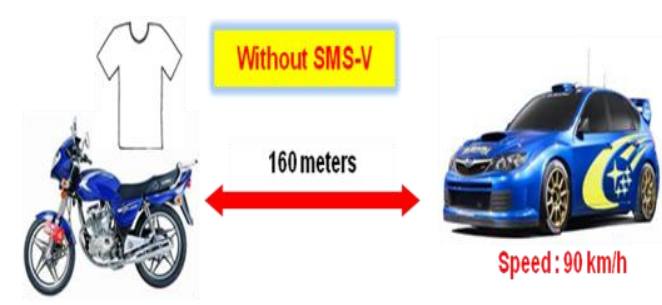

Car driver has only 6 second to act upon encountering the motorcycle.

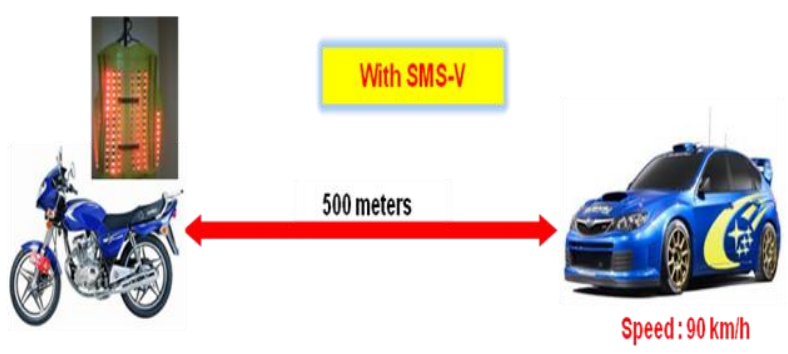

Car driver has more than 20 second to act upon encountering the motorcycle.

Fig. 8. Distance difference for with and without innovative safety vest.

If a vehicle such as car and lorry at a speed of $90 \mathrm{~km} / \mathrm{h}$ bump with a motorcyclist, the vehicle only has 6 seconds to take appropriate action to the situation. SMS-V which is developed from this research also able to assist other road users about the presence of a motorcyclist at a distance of 500 meters, which is three times better than normal conditions.

Fig. 9 shows the graph where time to alert in seconds versus speed of other vehicle in kilometer per hour $(\mathrm{km} / \mathrm{h})$. 
From the graph, it illustrates that, if other road users increase their vehicle speed, the time to identify motorcyclists on the road was exponential decline patterned; regardless using or not the safety vest. Fortunately, a motorcycle rider who is wearing the safety vest can be identified much earlier, approximately three times better if compared to without wearing the vest

Referred to the Fig. 10, the exterior of the radar is a speed of vehicle that has been distinguished; and the center point of radar is the beginning of time. The radar also shows the performance comparison of two situations; with and without SMS-V. It demonstrates the blue line (without SMS-V) is closer to the center but the red lines (with SMS-V) are avoiding the center point. It proves that, the use of safety vest is very much better than normal.

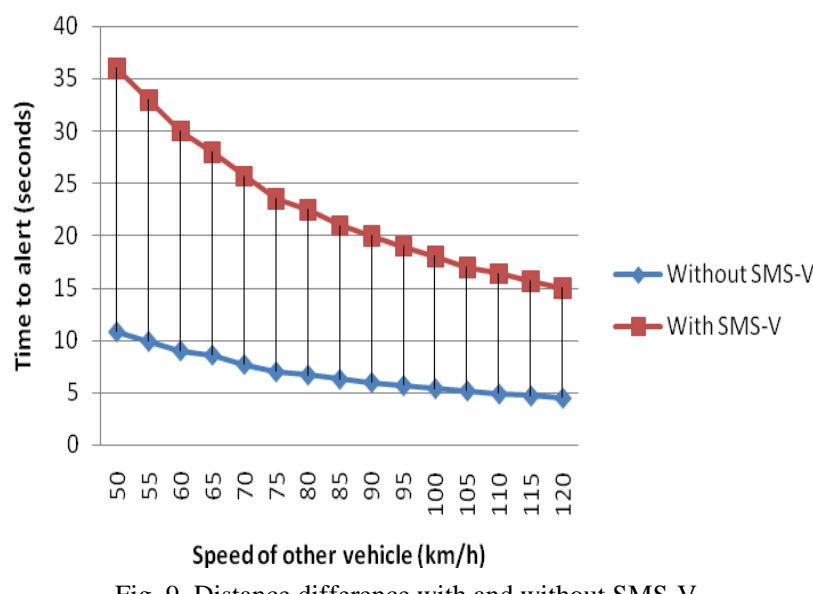

Fig. 9. Distance difference with and without SMS-V.

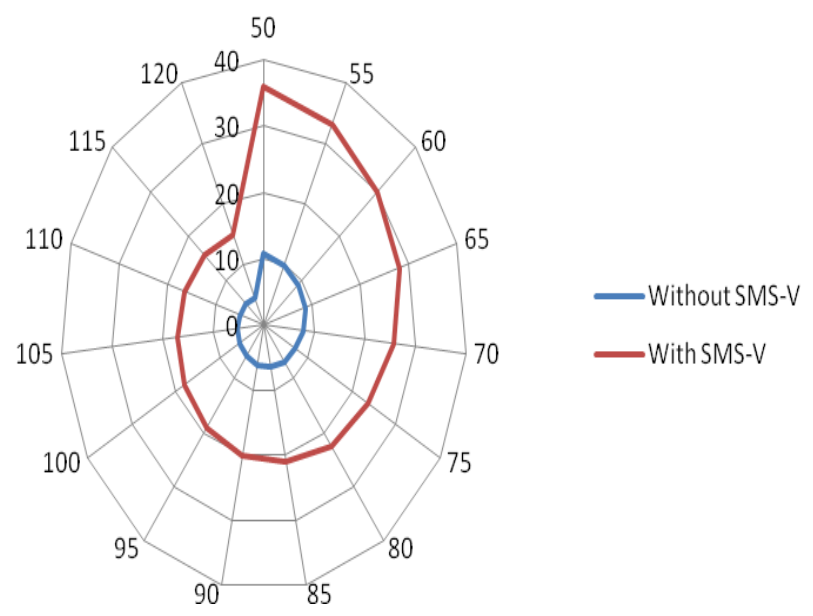

Fig. 10. Performance comparison in radar pattern.

\section{CONCLUSION}

This research has developed a Smart Motorcycle Safety Vest (SMS-V) that has several advantages which are very important in order to increase the visibility of other road user to the motorcyclist especially at night. The employment of simple RF circuit in this project has made the safety vest more dynamic and futuristic. Referring to the experimental results, a motorcyclist would be safer if wearing a proposed safety vest because the motorcyclists can be observed more clearly almost two times better than normal vision. This research has a very high impact where it can be as an alternative way in reducing the number of motorcycle accidents in Malaysia. Besides that, it is believed that this research capable to safe many motorcyclists especially young people and simultaneously help the country, not to run out of human capital.

\section{ACKNOWLEDGMENT}

The authors would like to express sincere gratitude to Universiti Teknikal Malaysia Melaka (UTeM), Malaysia for sponsored the fees for Malaysia's patent filling application. The patent filing number: PI2011003369 and was registered 14 May 2011. In addition, the authors also would like to thank you to JPJ Melaka, JKJR Melaka and MKJR Melaka for their support and advice throughout this research activity.

\section{REFERENCES}

[1] Driving Education Curriculum, Road Transport Department of Malaysia (JPJ), Ministry of Transport, Malaysia, 2010.

[2] H. M. Atiq, U. Farooq, and R. Ibrahim, "Vehicle detection and shape recognitiopn using optical sensors," in Proc. the Bizarre Fruit Postgraduate Confenrence, UK, 2010, pp. 107-123.

[3] J. Hirasawa and M. Kakikura, "Motion analysis of motorcycles: A study on DCT mechanism," in Proc. the Bizarre Fruit Postgraduate Confenrence, UK, 2010, pp. 127-131.

[4] Y. Lao, J. Remillard, and D. Hoetzer, "Pedestrian Detection in Near-Inferared Night vision System," presented at the 2010 IEEE Intelligent Vehicles Sysmposium Universitty of California, San Diego, USA, CA, June 21-24, 2010.

[5] A. A. M. Assidiq, O. O. Khalifa, R. Islam, and S. Khan, "Real time lane detection for autonomous vehicles," in Proc. the International Conference on Computer and Communication Engineering, Kuala Lumpur, Malaysia, 2008, pp. 107-123.

[6] E. D. Bekiaris, A. Spadoni, and S. I. Nikolaou, "Saferider Project : New safety and confort in powered two wheelers," presented at the 2010 IEEE Intelligent Vehicles Sysmposium Universitty of California, San Diego, USA, CA, June 21-24, 2010.

[7] M. Pieve, F. Tesauri, and A. Spadoni, "Mitigation Accident Risk in Powered Two Wheelers domain: Improving effectiveness of Human Machine Interface Collision Avoidance System in Two Wheelers," Humans System Interaction 2009- University of Catania, Catania, Italy, May 21-23, 2009.

[8] E. D. Bekiaris, A. Spadoni, and S. I. Nikolaou, "Saferider Project: New Safety and Comfort in Powered Two Wheelers," Humans System Interaction 2009- University of Catania, Catania, Italy, May 21-23, 2009.

[9] E. C. Restauro, "Motorcyclist garment with illuminated traffic signals," U.S. Patent 6,558,016 B1, May 6, 2003.

[10] H. G. Ross, Jr. and B. Wilcox, "Brake light warning system for safety helmets and method of operation," U.S. Patent 7,109,857 B2, September 19, 2006

[11] V. M. Pacheco and C. H. Kim, "Motorcycles safety brake and running light for a jacket or vest," U.S. Patent 12 290182,October 28, 2008

[12] A. Z. Shukor, M. H. Jamaluddin, and M. F. Basar, "An Automated Remote Messaging System Using GSM Technology," in Proc. The $2^{\text {nd }}$ International Conference on Engineering and ICT, Melaka, Malaysia February 2010, pp. 216-219.

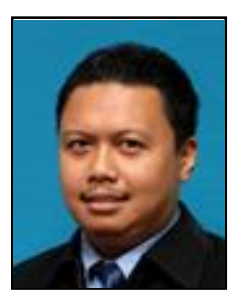

Mohd Farriz Basar was born in Kuala Lumpur, Malaysia on November 9, 1979. He obtained his Master and Degree in Electrical Engineering from Universiti Teknologi Malaysia, Skudai, Johor in 2001 and 2009 respectively. His major fields of study are high voltage power system and renewable energy technologies

He has an experience as Research and Development (R\&D) Engineer in electrical power industries about 5 years from 2001 until 2005. He worked at EPE Power Corporation Bhd at N Sembilan, Malaysia. He have been to KEMA Testing Centre, Netherlands for 3 months in order to conduct the type test of the transformer and switchgear. Now he is working as a Lecturer in Universiti Teknikal Malaysia Melaka (UTeM), Malaysia from 2005 until now. As a main author, he has published about 30 conference papers and journal in IEEE. In addition, he has 
published one book chapter in Energy Storage in the Emerging Era of Smart Grids, InTechWEB, Crotia, 2011, ISBN 978-953-307-269-2, pp. 89-110. Currently, his research is focussing in renewable energy techonologies especially in pico hydro generation system.

Mr. Farriz is a member of The Institution of Engineers Malaysia (IEM). He is also an ambassador for ASEAN Academy of Engineering and Technology (AAET) Association since 2012. Mohd Farriz have been selected as winners to represent Malaysia in the "ASEAN Country Winner" with his contribution in the field of Green Technology Entrepreneurship (Green Entrepreneur). He was also among the four best researchers in Southeast Asia selected to receive the "Excellent Prize Winner" in the Southeast Asian level.

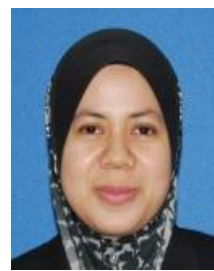

Nor Hazana Abdul Razik was born in Pahang, Malaysia on January 15, 1979. She obtained his Degree in Chemical Engineering from Universiti Teknologi Malaysia, Skudai, Johor in 2001. His major fields of study are in Physics Science and Petroleum Refinery Technologies.

From 2002 until now, she is work as a Physics Teacher at MARA Junior Science College,

Melaka, Malaysia. She is the co-author for one book chapter published in Energy Storage in the Emerging Era of Smart Grids, InTechWEB, Crotia, 2011, ISBN 978-953-307-269-2, pp. 89-110. Currently, her research is focussing in applying physics technologies especially in product innovation development.

Mrs Nor Hazana is a member of Board of Engineer Malaysia (BEM). In 2010, her college has won second place for the Physics Scientist Challenge in the national (Malaysia) level competition. Due to the excellent achievement, in 2011, she was appointed as Technical Provider in Physics Scientist Challenge for MARA Junior Science College, Malaysia 